\title{
Calcium-induced aggregation of archaeal bipolar tetraether liposomes derived from the thermoacidophilic archaeon Sulfolobus acidocaldarius
}

\author{
ROBY KANICHAY, ${ }^{1}$ LAWRENCE T. BONI, ${ }^{2}$ PETER H. COOKE,${ }^{3}$ TAPAN K. KHAN ${ }^{1}$ and \\ PARKSON LEE-GAU CHONG ${ }^{1,4}$ \\ ${ }^{1}$ Department of Biochemistry, Temple University School of Medicine, Philadelphia, PA 19140, USA \\ 2 Transave Inc., 11 Deer Park Drive, Suite 117, Monmouth, NJ 08852, USA \\ ${ }^{3}$ USDA, Eastern Regional Research Center, 600 East Mermaid Lane, Wyndmoor, PA 19038, USA \\ ${ }^{4}$ Author to whom correspondence should be addressed (pchong02@temple.edu)
}

Received November 18, 2002; accepted June 22, 2003; published online July 18, 2003

Summary Previously, we showed that the proton permeability of small unilamellar vesicles (SUVs) composed of polar lipid fraction E (PLFE) from the thermoacidophilic archaeon Sulfolobus acidocaldarius was remarkably low and insensitive to temperature (Komatsu and Chong 1998). In this study, we used photon correlation spectroscopy to investigate the time dependence of PLFE SUV size as a function of $\mathrm{Ca}^{2+}$ concentration. In the absence of $\mathrm{Ca}^{2+}$, vesicle diameter changed little over 6 months. Addition of $\mathrm{Ca}^{2+}$, however, immediately induced formation of vesicle aggregates with an irregular shape, as revealed by confocal fluorescence microscopy. Aggregation was reversible upon addition of EDTA; however, the reversibility varied with temperature as well as incubation time with $\mathrm{Ca}^{2+}$. Freeze-fracture electron microscopy showed that, after a long period of incubation ( 2 weeks) with $\mathrm{Ca}^{2+}$, the PLFE vesicles had not just aggregated, but had fused or coalesced. The initial rate of vesicle aggregation varied sigmoidally with $\mathrm{Ca}^{2+}$ concentration. At $\mathrm{pH}$ 6.6, the threshold calcium concentration $\left(C_{\mathrm{r}}\right)$ for vesicle aggregation at 25 and $40^{\circ} \mathrm{C}$ was 11 and $17 \mathrm{mM}$, respectively. At pH 3.0, the $C_{\mathrm{r}}$ at $25^{\circ} \mathrm{C}$ increased to $25 \mathrm{mM}$. The temperature dependence of $C_{\mathrm{r}}$ may be attributable to changes in membrane surface potential, which was -22.0 and $-13.2 \mathrm{mV}$ at 25 and $40{ }^{\circ} \mathrm{C}$, respectively, at $\mathrm{pH} 6.6$, as determined by 2-( $p$-toluidinyl)naphthalene-6-sulfonic acid fluorescence. The variation in surface potential with temperature is discussed in terms of changes in lipid conformation and membrane organization.

Keywords: fluorescence, light scattering, membranes, microscopy, $\mathrm{pH}$, surface potential, temperature, vesicle size.

\section{Introduction}

The major lipid components of the plasma membrane of the thermoacidophilic archaeon Sulfolobus acidocaldarius are tetraether lipids (De Rosa et al. 1986, Langworthy and Pond 1986, Kates 1992), among which the polar lipid fraction E (PLFE) is the main constituent (Lo and Chang 1990). The
PLFE contains a mixture of bipolar tetraether lipids with either a glycerol dialkyl calditol tetraether (GDNT; also called calditoglycerocaldarchaeol) or a glycerol dialkyl glycerol tetraether (GDGT; also called caldarchaeol) skeleton (Figure 1) (Lo and Chang 1990, Sugai et al. 1995, Gliozzi et al. 2002). Both GDGT and GDNT have bisubstituted polar head groups and are thus designated bipolar tetraether lipids. Glycerol dialkyl calditol tetraether ( $90 \%$ of total PLFE) has phosphomyo-inositol on the glycerol end and $\beta$-glucose on the calditol end, whereas GDGT ( 10\% of total PLFE) has phosphomyo-inositol attached to one glycerol and $\beta$-D-galactosyl-Dglucose to the other glycerol skeleton. The phospho-myoinositol groups of PLFE lipids are oriented toward the cytoplasmic side of the cell's plasma membrane (De Rosa et al. 1983). The nonpolar regions of these lipids consist of a pair of 40-carbon biphytanyl chains, each of which contains up to four cyclopentane rings. The number of cyclopentane rings increases with increasing growth temperature (De Rosa et al. 1980).

In aqueous solution, PLFE lipids form stable multilamellar and unilamellar liposomes (Lo and Chang 1990, Elferink et al. 1992, Bagatolli et al. 2000) in which the lipids span the entire lamellar structure, forming monomolecular membranes (Elferink et al. 1992). Liposomes composed of PLFE lipids exhibit rates of proton permeation and dye leakage that are unusually low and insensitive to temperature (In't Veld et al. 1992, Chang 1994, Elferink et al. 1994, van de Vossenberg et al. 1995, Komatsu and Chong 1998). These traits have been attributed to the unique chemical structure of bipolar tetraether lipids and their organization within membranes, particularly the network of hydrogen bonds between polar head groups, the rigid and tight packing of lipids within the membrane, and the negative charges on the membrane surface (Elferink et al. 1994, Relini et al. 1994, van de Vossenberg et al. 1995, Komatsu and Chong 1998). The remarkable thermostability of proton permeation across PLFE membranes has provided a partial explanation of how $S$. acidocaldarius can grow at high temperatures $\left(65-83{ }^{\circ} \mathrm{C}\right.$ ) (van de Vossenberg et al. 1995) in 

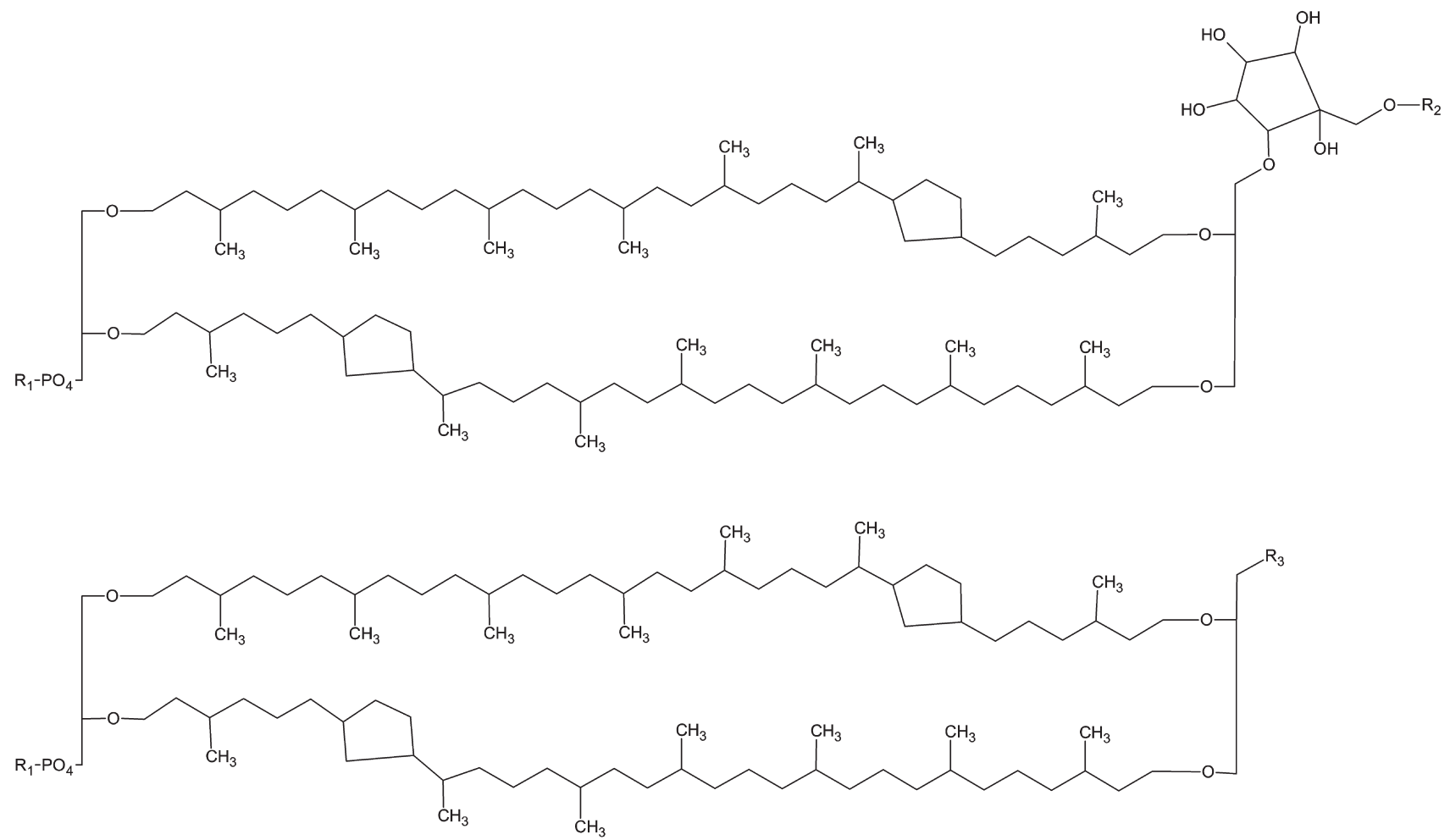

Figure 1. Structures of PLFE lipids: (top) glycerol dialkyl calditol tetraether (GDNT) and (bottom) glycerol dialkyl glycerol tetraether (GDGT). Abbreviations: $R_{1}=$ inositol; $R_{2}=\beta$-D-glucopyranose; and $R_{3}=\beta$-D-galactosyl- $\beta$-D-glucopyranose. The number of cyclopentane rings in each biphytanyl chain can vary from 0 to 4 .

acidic environments $(\mathrm{pH} 2-3)$ and yet maintain the intracellular compartment at pH 6.5 (Brock et al. 1972).

In addition to thermal and acid stability, PLFE and other archaeal bipolar tetraether liposomes exhibit remarkable resistance to mechanical stress and the actions of phospholipases, bile salts and serum proteins (reviewed in Gliozzi and Relini 1996). Because of their extraordinary stability, which permits sterilization (Choquet et al. 1994) and filtration (Bauer et al. 1983), bipolar tetraether liposomes have found wide application in immunoassays (Tomioka et al. 1994) and in vaccine and drug delivery (Ring et al. 1986, Sprott 1992, Elferink et al. 1994, Freisleben et al. 1995, Gliozzi and Relini 1996, Sprott et al. 1997, Krishnan et al. 2000, Patel et al. 2000). Although stability against macrophages and other bioactive species is desirable in liposomes used as drug delivery vehicles, high membrane stability also hinders the release of entrapped drugs. Therefore, a compromise between membrane stability and drug release is required. It is known that drug release from liposomes composed of typical phospholipid bilayers can be facilitated via fusion and lipid mixing, both of which are preceded by vesicle aggregation (Boni et al. 1984, Bentz and Duzgunes 1985). Hence, it is of interest to investigate the mechanisms underlying the aggregation and fusion processes of PLFE liposomes.

Previous studies (Relini et al. 1994, 1996) reported that fusogenic agents such as calcium chloride and polyethylene glycol induced fusion between vesicles derived from total lipid extracts of the thermoacidophilic archaeon Sulfolobus solfataricus. However, with vesicles made from the P2 bipolar tetraether lipid fraction of the same archaeon, only vesicle aggregation, not fusion, was observed. The total lipid extracts of S. solfataricus contain both bisubstituted (e.g., GDGT and GDNT) and monosubstituted tetraether lipids, whereas the P2 fraction contains only bisubstituted tetraether lipids (reviewed in Gliozzi et al. 2002). Liposomal membranes made from the P2 fraction have a strict lamellar structure (Gulik et al. 1988), and fusion occurs only when this lamellar structure is disturbed (Relini et al. 1994, 1996). Furthermore, $\mathrm{Ca}^{2+}$-induced aggregation or fusion of bipolar tetraether liposomes occurs on the time scale of tens of minutes (Relini et al. 1994), which is much slower than that of monopolar diester liposomes (Wilschut et al. 1980, Hui et al. 1988). Moreover, unlike most monopolar diester lipid membranes, bipolar tetraether lipid monolayers show no detectable changes in surface tension even when fusion occurs (Relini et al. 1994). As such, bipolar tetraether liposomes possess many unusual properties related to membrane aggregation and fusion that warrant further study.

In this study, we have focused on the calcium-induced aggregation of PLFE liposomes derived from the thermoacidophilic archaeon $S$. acidocaldarius. The PLFE fraction of $S$. acidocaldarius is equivalent to the $\mathrm{P} 2$ fraction of $S$. solfataricus (reviewed in Gliozzi et al. 2002). Aggregation was monitored in this study because it is the first step involved in 
membrane fusion and lipid mixing and because aggregation of bipolar tetraether liposomes has not been studied extensively. In the present study, dynamic light scattering revealed that, in the absence of $\mathrm{Ca}^{2+}$, there was little change in PLFE vesicle diameter over 6 months. Addition of sufficient amounts of $\mathrm{Ca}^{2+}$, however, induced immediate vesicle aggregation, which was largely reversible by EDTA. The initial rate of $\mathrm{Ca}^{2+}$-induced vesicle aggregation and the reversal of this aggregation by EDTA were examined at different temperatures, $\mathrm{pH}$, and $\mathrm{Ca}^{2+}$ concentrations. The morphology of the aggregates was studied by freeze-fracture and confocal fluorescence microscopy. The temperature and $\mathrm{pH}$ dependencies of the threshold $\mathrm{Ca}^{2+}$ concentration for vesicle aggregation are discussed in relation to changes in membrane surface potential and lipid organization and conformation.

\section{Materials and methods}

\section{Materials}

Sulfolobus acidocaldarius cells (strain DSM639, ATCC, Rockville, MD) were grown aerobically and heterotrophically at $69-70{ }^{\circ} \mathrm{C}$ and $\mathrm{pH} 2.5-3.0$. Growth was monitored by absorbance at 420 and $540 \mathrm{~nm}$. Cells were harvested just before the stationary phase. Polar lipid fraction E lipids were isolated from dry cells as previously described (Lo and Chang 1990).

1-Palmitoyl-2-oleoyl-L- $\alpha$-phosphatidylcholine (POPC) and $N$-4-nitrobenzo-2-oxa-1,3-diazole phosphatidylethanolamine (N-NBD-PE) were purchased from Avanti Polar Lipids (Alabaster, AL) and 2-( $p$-toluidinyl)naphthalene-6-sulfonate (TNS) was obtained from Molecular Probes (Eugene, OR). Cholesterol (Sigma, St. Louis, MO) was recrystallized from ethanol.

\section{Liposome preparation}

For vesicles without fluorescent probe, PLFE was dispersed in 64:25:4 chloroform:methanol:water (v/v). The solvents were evaporated under nitrogen and the lipid was dried under high vacuum for $\sim 12 \mathrm{~h}$. Vesicles with the fluorescent probe $\mathrm{N}$ NBD-PE were generated in two steps (Khan and Chong 2000). First, PLFE and N-NBD-PE were mixed in 64:25:4 chloroform:methanol:water ( $\mathrm{v} / \mathrm{v})$, then dried as described above. Second, the dried lipid film was resuspended in 65:25:10 chloroform:methanol:water (v/v) and again dried under nitrogen followed by high vacuum for $\sim 12 \mathrm{~h}$.

To the dried PLFE film (with or without N-NBD-PE), appropriate amounts of either $100 \mathrm{mM}$ citric acid/sodium citrate buffer ( $\mathrm{pH}$ 3.0) or $50 \mathrm{mM} \mathrm{KCl}(\mathrm{pH} \mathrm{6.6)} \mathrm{containing} 0.02 \%$ $\mathrm{NaN}_{3}$ were added. The mixture was vigorously vortexed at $65{ }^{\circ} \mathrm{C}$ for $12 \mathrm{~min}$ to generate multilamellar vesicles (MLVs). Unilamellar vesicles were made from MLVs by the freezethaw and extrusion method (Hope et al. 1985). Briefly, MLVs were subjected to at least five cycles of freezing (dry ice/acetone) and thawing $\left(65^{\circ} \mathrm{C}\right)$. Vesicles were then extruded at $65^{\circ} \mathrm{C}$ in a lipid extruder (Lipex, Vancouver, BC) through two stacked polycarbonate membranes $(1 \mu \mathrm{m}$ pore size for confo- cal experiments and 50,100 or $200 \mathrm{~nm}$ pore sizes for the other experiments) under $\mathrm{N}_{2}$ gas pressure $(400,600$ and $5000 \mathrm{kPa}$ for pore sizes of $1 \mu \mathrm{m}, 200 \mathrm{~nm}$ and $<200 \mathrm{~nm}$, respectively). In N-NBD-PE-labeled PLFE liposomes, the ratio of probe to PLFE was 1:500.

\section{Measurement of surface potential}

To determine the surface potential of PLFE liposomes, the steady-state fluorescence intensity of the membrane probe TNS was measured. This probe is an anionic amphipathic molecule that binds strongly to lipid membranes (Huang and Charlton 1972, Easter et al. 1978, Lakowicz and Hogen 1981), mainly via van der Waals interactions (Seelig and Ganz 1991). In aqueous medium, TNS has a low quantum yield; however, upon binding to lipid vesicles, the fluorescence intensity of TNS ( $I_{\mathrm{L}}$; dimensionless) is enhanced. Both $I_{\mathrm{L}}$ and the concentration of TNS in the bulk solution $\left([\mathrm{TNS}]_{b} ; \mu \mathrm{M}\right)$ are related to membrane surface potential $\left(\Psi_{0} ; \mathrm{mV}\right)$ according to Equation 1 (Eisenberg et al. 1979, Cafiso et al. 1989):

$$
I_{\mathrm{L}} /[\mathrm{TNS}]_{\mathrm{b}}=\beta[\mathrm{L}] e^{F \Psi_{\mathrm{o}} / R T}
$$

where $\beta$ is a proportionality constant, $F$ is the Faraday constant $\left(9.65 \times 10^{4} \mathrm{C} \mathrm{mol}^{-1}\right), R$ is the gas constant $\left(8.3145 \mathrm{~J} \mathrm{~mol}^{-1}\right.$ $\left.\mathrm{K}^{-1}\right), T$ is absolute temperature and [L] is lipid concentration $(\mu \mathrm{M})$.

We measured $I_{\mathrm{L}}$ as a function of $[\mathrm{TNS}]_{\mathrm{b}}$ at a fixed lipid concentration $(16 \mu \mathrm{M})$. At constant $[\mathrm{L}]$, there is a linear relationship between $I_{\mathrm{L}}$ and $[\mathrm{TNS}]_{\mathrm{b}}$, and the slope of the plot of $I_{\mathrm{L}}$ versus $[\mathrm{TNS}]_{\mathrm{b}}$ gives $\Psi_{\mathrm{o}}$. Appropriate amounts of TNS were incubated with lipid vesicles at the desired temperature for 4-6 h prior to measurement of $I_{\mathrm{L}}$; thereafter, no further enhancement of fluorescence was observed. This experiment was performed with two lipid systems: PLFE unilamellar vesicles and POPC unilamellar vesicles containing $19 \mathrm{~mol} \%$ cholesterol (prepared as described in Komatsu and Chong 1998). At neutral $\mathrm{pH}$, the $\Psi_{\mathrm{o}}$ of the zwitterionic lipid POPC is zero. Then,

$$
I_{\mathrm{PLFE}}[\mathrm{TNS}]_{\mathrm{b}, \mathrm{POPC}} / I_{\mathrm{POPC}}[\mathrm{TNS}]_{\mathrm{b}, \mathrm{PLFE}}=e^{F \Psi_{\mathrm{o}, \mathrm{PLFE}} / R T}
$$

where $I_{\mathrm{PFLE}}$ and $I_{\mathrm{POPC}}$ are the fluorescence intensities of TNS with PLFE and POPC liposomes, respectively, $\Psi_{\mathrm{o}, \mathrm{PLFE}}$ is the surface potential of PLFE liposomes and [TNS $]_{\mathrm{b}, \text { lipid }}$ is the bulk concentration of TNS when the designated lipid is used. The liposomes with probe were stirred while fluorescence intensity was measured with an SLM 8000C fluorometer (SLM Instruments, Urbana, IL). The excitation wavelength was $320 \mathrm{~nm}$ (2-nm band-pass) and the emission was observed between 380 and $560 \mathrm{~nm}$ (8-nm band-pass). Sample temperatures were maintained with a circulating bath. Blank readings (vesicles or TNS in buffer) were subtracted from the sample $I_{\mathrm{L}}$ readings.

\section{Photon correlation spectroscopy}

The hydrodynamic diameters of the extruded PLFE vesicles were measured by photon correlation spectroscopy using a 
Malvern Zetasizer 1000HAS spectrometer (Malvern Instruments, Worcestershire, U.K.). The light source was a $10 \mathrm{~mW}$ He-Ne laser $(633 \mathrm{~nm})$ and the scattered light was measured at a right angle using an avalanche photodiode detector. The instrument was calibrated with $200-\mathrm{nm}$ latex beads in $10 \mathrm{mM}$ $\mathrm{NaCl}$. The solution was filtered through a $0.22-\mu \mathrm{m}$ syringe filter and degassed prior to measurements. Because very dilute solutions were used, refractive index and viscosity values for water were used for calculation of hydrodynamic diameters. Specifically, the refractive index was 1.33 at all temperatures examined, and the viscosity was $0.891,0.653$ and $0.488 \mathrm{cP}$ ( $1 \mathrm{cP}=0.001 \mathrm{~Pa} \mathrm{~s}$ ) at 25,40 and $54{ }^{\circ} \mathrm{C}$, respectively (Weast 1987). Data were analyzed with the Contin algorithm (Malvern Instruments), which calculates the $\mathrm{Z}$-average size and polydispersity. The former is the mean vesicle hydrodynamic diameter and the latter is a measure of the width of the vesicle size distribution. To induce aggregation, various volumes of $204 \mathrm{mM} \mathrm{CaCl}_{2}$ were added to a solution of PLFE vesicles. To reverse aggregation, an appropriate amount of $100 \mathrm{mM}$ EDTA was added.

\section{Freeze-fracture electron microscopy}

Samples without cryoprotectant were placed between copper specimen carriers (Balzers, Liechtenstein) and rapidly plunged into liquid propane. Fracturing and replicating was performed at $-115^{\circ} \mathrm{C}$ in a Balzers BAF 400T Freeze-Etch unit. Replicas were cleaned with $\mathrm{NaHClO}_{3}$ solution and viewed on a Philips 300 transmission electron microscope at a typical magnification of $27,000 \times$.

\section{Confocal fluorescence microscopy}

Liposomes labeled with N-NBD-PE were incubated with or without $\mathrm{Ca}^{2+}$ and then adsorbed to a glass coverslip. Images were captured with a Model TCS-SP confocal laser scanning microscope (Leica Microsystems, Exton, PA) using an ar- gon/krypton laser for excitation at $488 \mathrm{~nm}$. Fluorescence (around $\sim 534 \mathrm{~nm}$ ) was detected in the photon counting mode as a single channel through a $100 \times$ oil-immersion lens.

\section{Results and discussion}

In this study, we investigated the kinetics of the change in size of PLFE SUVs as a function of $\mathrm{Ca}^{2+}$ concentration. The photon correlation spectroscopy data show that, in the absence of $\mathrm{Ca}^{2+}$, the mean diameter of PLFE SUVs in $50 \mathrm{mM} \mathrm{KCl}$ is stable for 6 months at room temperature $\left(\sim 24^{\circ} \mathrm{C}\right.$ ) (Figure 2). Furthermore, the mean size of PLFE SUVs remained constant at temperatures ranging from 25 to $55^{\circ} \mathrm{C}$ (data not shown).

The addition of $\mathrm{Ca}^{2+}$, however, had a pronounced effect on particle size. Figure 3 shows the effect of $\mathrm{Ca}^{2+}$ concentration on mean PLFE particle diameter over time in $50 \mathrm{mM} \mathrm{KCl}$ at $40{ }^{\circ} \mathrm{C}$. At low $\mathrm{Ca}^{2+}$ concentrations (e.g., $<10.2 \mathrm{mM}$ ), PLFE unilamellar vesicles showed no appreciable change in size over time. However, at higher $\mathrm{Ca}^{2+}$ concentrations (e.g., 15.0$25.1 \mathrm{mM}$ ), mean particle diameter increased over time (Figure 3 ). The vesicle size distribution also grew broader over time. The increase in particle size is attributable either to vesicle aggregation or to fusion or coalescence (lipid mixing). In either case, the change in size is presumably triggered by binding of $\mathrm{Ca}^{2+}$ to the negatively charged phospho-myo-inositol groups, followed by charge neutralization, complex formation and membrane structural changes (Wilschut et al. 1985). Figure 3 also shows that the rate of $\mathrm{Ca}^{2+}$-induced aggregation or fusion of PLFE liposomes is low (on the order of tens of minutes) compared with the rate of aggregation of negatively charged monopolar diester liposomes at comparable $\mathrm{Ca}^{2+}$ and lipid concentrations (on the order of seconds) (Sundler and Papahadjopoulos 1981).

Confocal fluorescence microscopy also showed that, in the absence of $\mathrm{Ca}^{2+}$, the diameter of the extruded vesicles was rel-

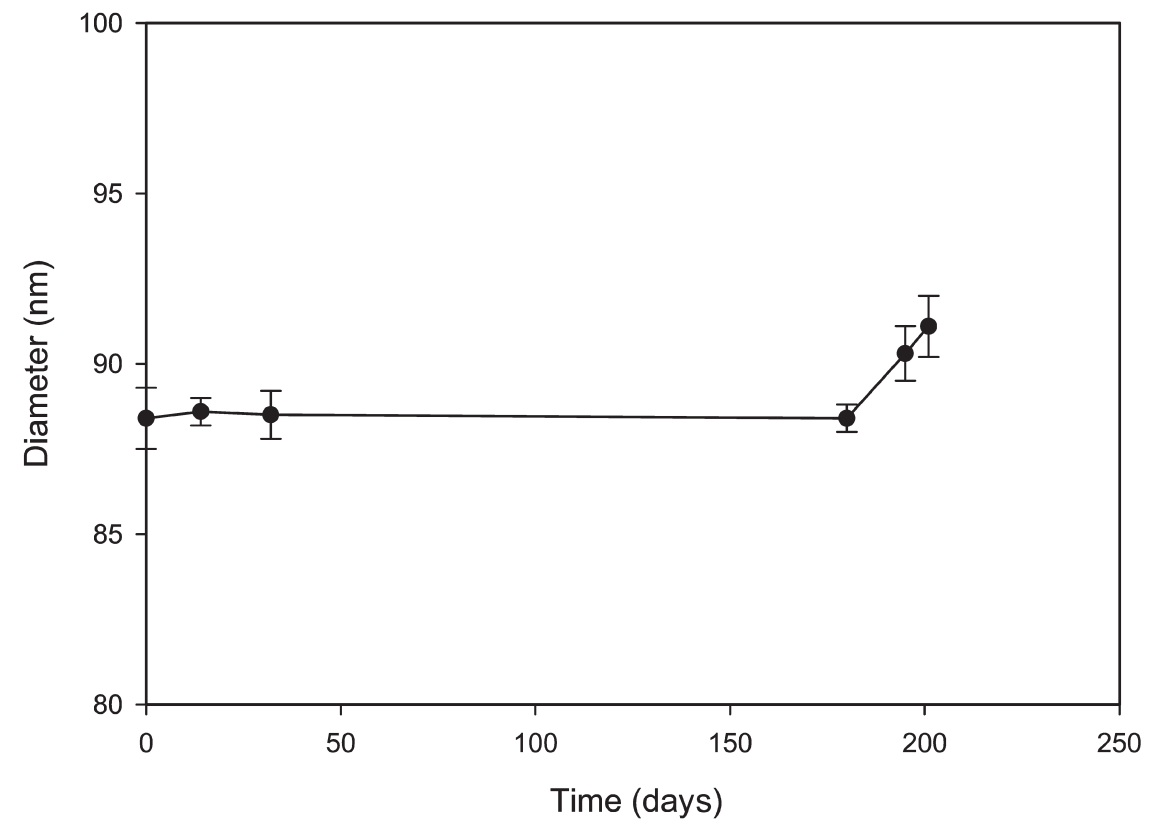

Figure 2. Vesicle size of PLFE small unilamellar vesicles as a function of storage time at room temperature in $50 \mathrm{mM} \mathrm{KCl}$. The PLFE concentration was $0.05 \mathrm{mM}$. 


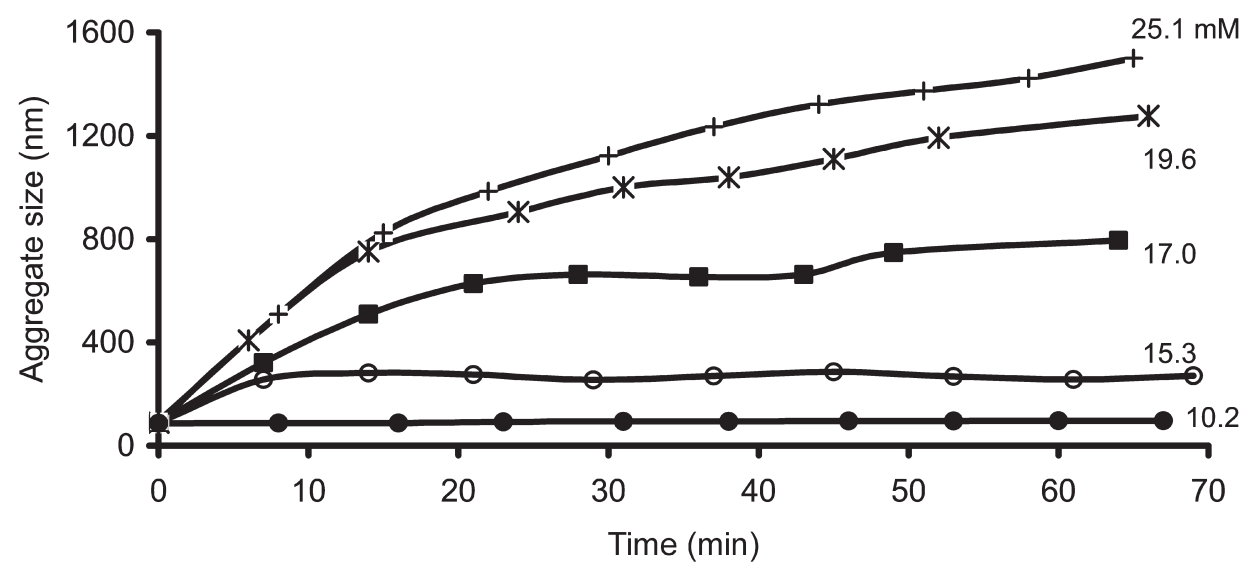

Figure 3. Effect of $\mathrm{Ca}^{2+}$ concentration $(10.2-25.1 \mathrm{mM})$ on the time course of mean PLFE particle diameter in $50 \mathrm{mM}$ $\mathrm{KCl}$ at $40{ }^{\circ} \mathrm{C}$.

atively uniform (initially about $500 \mathrm{~nm}$; Figure 4A). However, at high $\mathrm{Ca}^{2+}$ concentrations, vesicles formed aggregates with irregular shapes and heterogeneous sizes (Figure 4B). These observations are supported by the photon correlation spectroscopy data, which revealed an increase in size as well as a broadening of the size distribution. Note that the two studies used different vesicle preparations with different initial vesicle sizes.

As shown in Table 1, the increase in PLFE particle size following incubation with $12.5 \mathrm{mM} \mathrm{Ca}^{2+}$ for $4 \mathrm{~h}$ at $25^{\circ} \mathrm{C}$ was reversed $(\sim 98 \%)$ by addition of a twofold excess of EDTA (Wilschut et al. 1980, 1981), suggesting that little vesicle fusion had occurred. In conjunction with the decrease in size, the polydispersity also decreased (data not shown). Furthermore, the data in Table 1 demonstrate that the reversal of particle size change by EDTA is dependent on both temperature and the incubation time of the vesicles with $\mathrm{Ca}^{2+}$. At higher temperatures, and when the incubation time with $\mathrm{Ca}^{2+}$ is increased, the degree of reversal engendered by EDTA is decreased. These results strongly suggest that $\mathrm{Ca}^{2+}$ causes not only PLFE vesicle aggregation, but also some vesicle fusion or coalescence. However, if the $\mathrm{Ca}^{2+}$-induced size increase had been a result of fusion or coalescence only, the size increase would have been completely nonreversible by a twofold excess of EDTA (Leventis et al. 1986). These results are in agreement with previous findings that, at room temperature, $\mathrm{Ca}^{2+}$ induces aggregation, but not fusion, of vesicles made from the P2 lipid fraction from S. solfataricus (Relini et al. 1994, 1996). The PLFE fraction from $S$. acidocaldarius and the $\mathrm{P} 2$ fraction from $S$. solfataricus both consist primarily of bisubstituted tetraether lipids carrying negative charges at neutral $\mathrm{pH}$.

A possible explanation for the limited fusion of PLFE li-
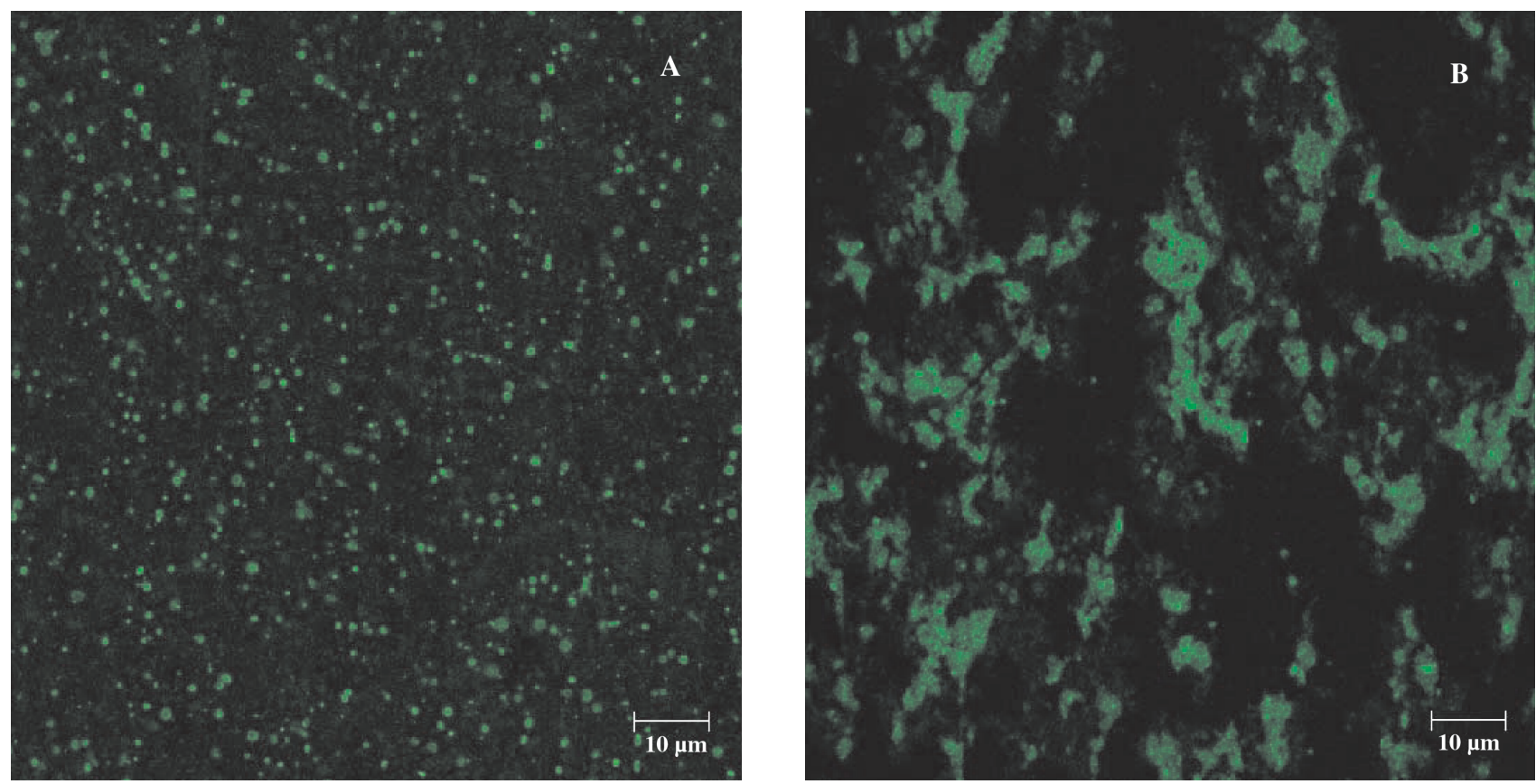

Figure 4. Confocal fluorescence images of N-NBD-PE-labeled PLFE large unilamellar vesicles in $50 \mathrm{mM} \mathrm{KCl}(\mathrm{A})$ without $\mathrm{Ca}^{2+}(\mathrm{mean}$ vesicle diameter $=499.4 \mathrm{~nm}$ ) and (B) with $35.3 \mathrm{mM} \mathrm{Ca}^{2+}$. 
Table 1. Effect of EDTA on $\mathrm{Ca}^{2+}$-induced aggregation of PLFE vesicles.

\begin{tabular}{|c|c|c|c|c|c|c|c|}
\hline \multirow[t]{2}{*}{ Temperature $\left({ }^{\circ} \mathrm{C}\right)$} & \multicolumn{4}{|c|}{ Vesicle aggregation } & \multicolumn{3}{|c|}{ Reversal of aggregation } \\
\hline & $\begin{array}{l}\text { Initial particle } \\
\text { diameter }(\mathrm{nm})\end{array}$ & {$\left[\mathrm{Ca}^{2+}\right](\mathrm{mM})$} & $\begin{array}{l}\text { Incubation } \\
\text { time (h) }\end{array}$ & $\begin{array}{l}\text { Resulting particle } \\
\text { diameter }(\mathrm{nm})\end{array}$ & {$[\mathrm{EDTA}](\mathrm{mM})$} & $\begin{array}{l}\text { Incubation } \\
\text { time (h) }\end{array}$ & $\begin{array}{l}\text { Final particle } \\
\text { diameter }(\mathrm{nm})\end{array}$ \\
\hline 25 & 117 & 12.5 & 4 & 1245 & 25 & 12 & 140 \\
\hline 25 & 90 & 10.0 & 154 & 2545 & 20 & 10 & 180 \\
\hline 40 & 89 & 19.6 & 120 & 2374 & 40 & 12 & 352 \\
\hline
\end{tabular}

posomes at $25^{\circ} \mathrm{C}$ after a brief (4-h) incubation with $\mathrm{Ca}^{2+}$ is the rigid and tight membrane packing in these liposomes (Kao et al. 1992, Chang 1994, Komatsu and Chong 1998, Bagatolli et al. 2000, Gabriel and Chong 2000, Khan and Chong 2000). Vesicle fusion would require a membrane defect or destabilization (Papahadjopoulos et al. 1977, 1990, Hui et al. 1981). Another possibility is that the bulky hydrated inositol group sterically inhibits fusion by preventing the formation of dehydrated complexes between the apposed PLFE vesicles, as is the case with phosphatidylinositol membranes, which do not undergo fusion following $\mathrm{Ca}^{2+}$-induced aggregation (Sundler and Papahadjopoulos 1981). In addition, a greater amount of energy would be expected to be required for the molecular rearrangements necessary for fusion of liposomes composed of bipolar lipids, because one head group would be expected to completely traverse the lipid core. Coalescence of liposomes composed of bipolar lipids would not occur in the manner typically observed for fusion of liposomes composed of monopolar lipids, where single monolayers interact to form hemifusion intermediates (Ellens et al. 1989). Note that, in many monopolar diester liposomes, divalent cation-induced vesicle aggregation is followed by immediate membrane fusion, which cannot be reversed by addition of EDTA.

Fusion or coalescence may occur as a result of impurities in the PLFE (Chang and Lo 1991). An alternative explanation is that calcium ions induce lateral segregation of the bulky phospho-myo-inositol groups in the plane of the membrane. As a result, the less bulky polar head groups (i.e., those with nonitol and glucose) may become more readily susceptible to dehydration, leading to hydrophobic interactions between the apposed vesicles and eventually to fusion or lipid mixing. Lipid lateral reorganization could be a slow process, on the time scale of minutes to days; this may explain why incubation of PLFE vesicles with $\mathrm{Ca}^{2+}$ for a longer period of time lowers the reversibility of vesicle size change by EDTA (Table 1).

The conclusions drawn from the EDTA results are supported by freeze-fracture electron microscopy data (Figure 5). Figure 5A shows the freeze-fracture micrograph of PLFE unilamellar vesicles in the absence of $\mathrm{Ca}^{2+}$. The mean diameter of these vesicles was $84 \mathrm{~nm}$. The liposomes were not aggregated and lacked a preferential membrane fracture plane, in agreement with previous results obtained with the P2 fraction from S. solfataricus (De Rosa et al. 1986, Gliozzi and Relini 1996). However, after incubation with $15.1 \mathrm{mM} \mathrm{CaCl}_{2}$ for 2 weeks, PLFE vesicles in $50 \mathrm{mM} \mathrm{KCl}$ had not just aggregated, they had fused or coalesced, as indicated by cross-fractured structures visible in the micrographs (Figure 5B). Cross-fractures would be anticipated where there are no bilayers, and thus no true fracture planes. Furthermore, the vesicles formed after incubation with $\mathrm{CaCl}_{2}$ did not consist of tight concentric layers. Our
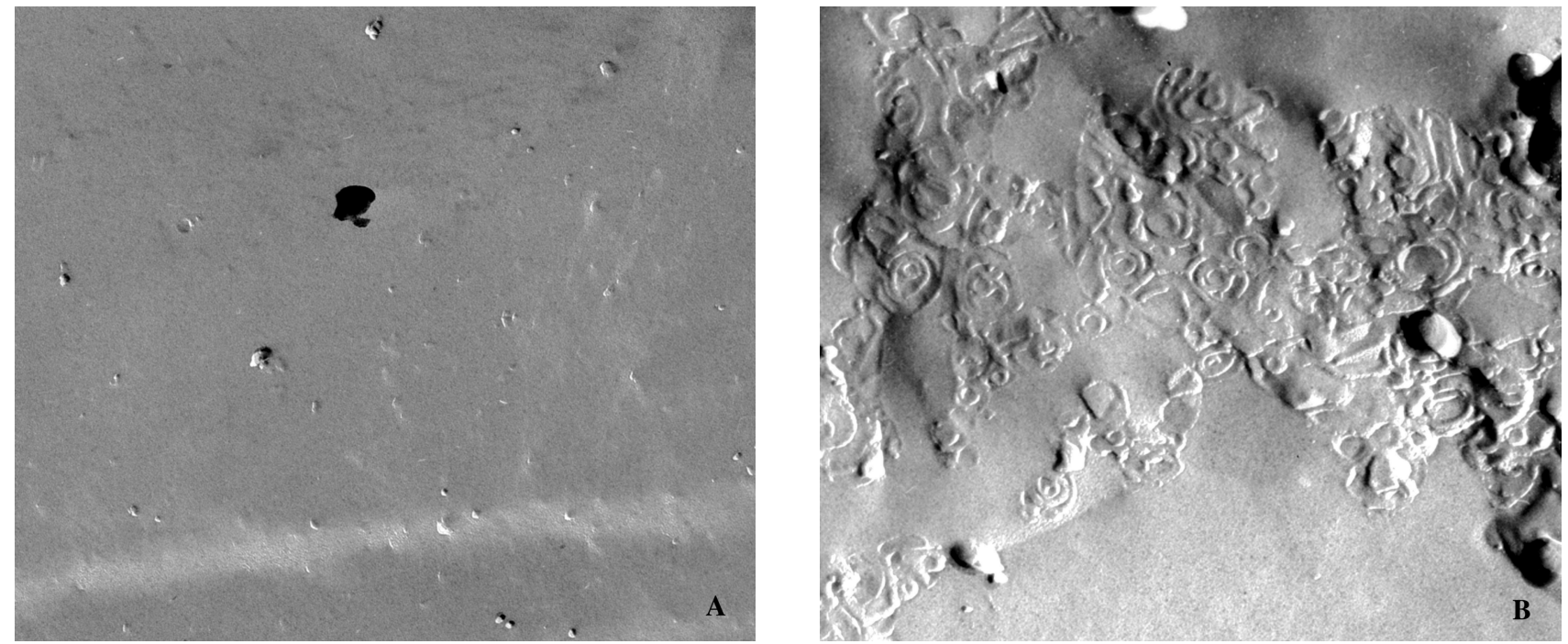

Figure 5. Electron micrographs of freeze-fracture replicas of $500 \mu \mathrm{l} \mathrm{of} 0.4 \mathrm{mg} \mathrm{ml}^{-1} \mathrm{PLFE}$ unilamellar vesicles in $50 \mathrm{mM} \mathrm{KCl}$. (A) Vesicles without $\mathrm{Ca}^{2+}$; mean vesicle diameter $\sim 84 \mathrm{~nm}$. (B) Vesicles incubated with $15.1 \mathrm{mM} \mathrm{Ca}^{2+}$ for 2 weeks. Magnification $=46,000 \times$. 
electron microscopy data are in agreement with observations made by Lo and Chang (1990), who looked at PLFE multilamellar vesicles. We initially observed unilamellar vesicles (Figure 5A), which coalesced to form multilamellar vesicles (multiple rings) after incubation with $\mathrm{Ca}^{2+}$ for about 2 weeks (Figure 5B). If the initial unilamellar PLFE vesicles had merely aggregated, not fused or coalesced, then we would have expected the vesicles in Figure $5 \mathrm{~B}$ to look like those shown in Figure $5 \mathrm{~A}$, but at a higher density.

The threshold $\mathrm{Ca}^{2+}$ concentration for PLFE vesicle aggregation can be determined from the photon correlation spectroscopy data. The first $15 \mathrm{~min}$ of data from the plot of mean vesicle diameter versus aggregation time (e.g., Figure 3) were fitted to a linear line, the slope of which gives the initial rate of vesicle aggregation. The initial rate of PLFE vesicle aggregation varied sigmoidally with $\mathrm{Ca}^{2+}$ concentration (Figure 6). The $\mathrm{Ca}^{2+}$ concentration corresponding to the midpoint of the abrupt change (50\% change) in vesicle size is the threshold calcium concentration $\left(C_{\mathrm{r}}\right)$ for vesicle aggregation. We found that the $C_{\mathrm{r}}$ increased with increasing temperature, but decreased with increasing $\mathrm{pH}$ (Table 2).

Because membrane surface charge may affect $\mathrm{Ca}^{2+}$ binding and thus change the value of $C_{\mathrm{r}}$, we determined the temperature dependence of the membrane surface potential of PLFE vesicles using TNS fluorescence. The surface potential of PLFE SUVs at $\mathrm{pH} 6.6$ and $25^{\circ} \mathrm{C}$ was determined to be $-22 \mathrm{mV}$ (Table 2), which is comparable with the published zeta potential $(-34.3 \mathrm{mV})$ for PLFE SUVs of similar sizes at $\mathrm{pH} 7.6$ and $20{ }^{\circ} \mathrm{C}$ (Komatsu and Chong 1998). The surface potential of PLFE liposomes decreased (i.e, became less negative) with increasing temperature (Table 2). When the surface potential is less negative, more calcium ions are required to form stable complexes with PLFE vesicles. This explains why $C_{\mathrm{r}}$ increases with increasing temperature (Table 2). The same rationale ex- plains why $C_{\mathrm{r}}$ increases with decreasing $\mathrm{pH}$ (Table 2). The negative charge on the phospho-myo-inositol group in PLFE lipids should be significantly lower at $\mathrm{pH} 3.0$ than at $\mathrm{pH}$ 6.6, leading to a lower surface potential on PLFE liposomes and a higher $C_{\mathrm{r}}$ at $\mathrm{pH} 3.0$ than at $\mathrm{pH}$ 6.6. This interpretation is consistent with the observed decrease in the threshold calcium concentration for lipid mixing with increasing phosphatidic acid (PA) content in PA-phosphatidylcholine mixtures (Leventis et al. 1986), as PA is negatively charged at neutral $\mathrm{pH}$.

Temperature may induce changes in polar head group orientation, leading to changes in dipole potential. However, Cafiso et al. (1989) found that the absorption of TNS to monopolar lipid membranes is independent of the dipole potential of the lipid head group, presumably because the charge of TNS is located such that it is unaffected by a change in dipole potential. Therefore, it is unlikely that a change in lipid dipole potential is responsible for the change in surface potential with temperature (Table 2), unless the location of TNS in PLFE liposomes is different from its location in non-archaeal monopolar lipid membranes.

Another possible explanation for the decrease in surface potential with increasing temperature is that higher temperatures induce more phospho-myo-inositol groups to turn toward the intravesicular side of the membrane. This explanation would be consistent with the previous finding that, in vivo, the phospho-myo-inositol moieties of bipolar tetraether lipids mainly face the intracellular compartment of thermoacidophilic archaea at the high growth temperatures characteristic of these microorganisms (De Rosa et al. 1983). However, from an energetic point of view, flip-flop of PLFE lipids in tightly packed membranes would be difficult to achieve. Nevertheless, a change in lipid transmembrane asymmetry has previously been proposed to explain why the rate and temperature sensitivity of proton permeation across PLFE liposomal mem-

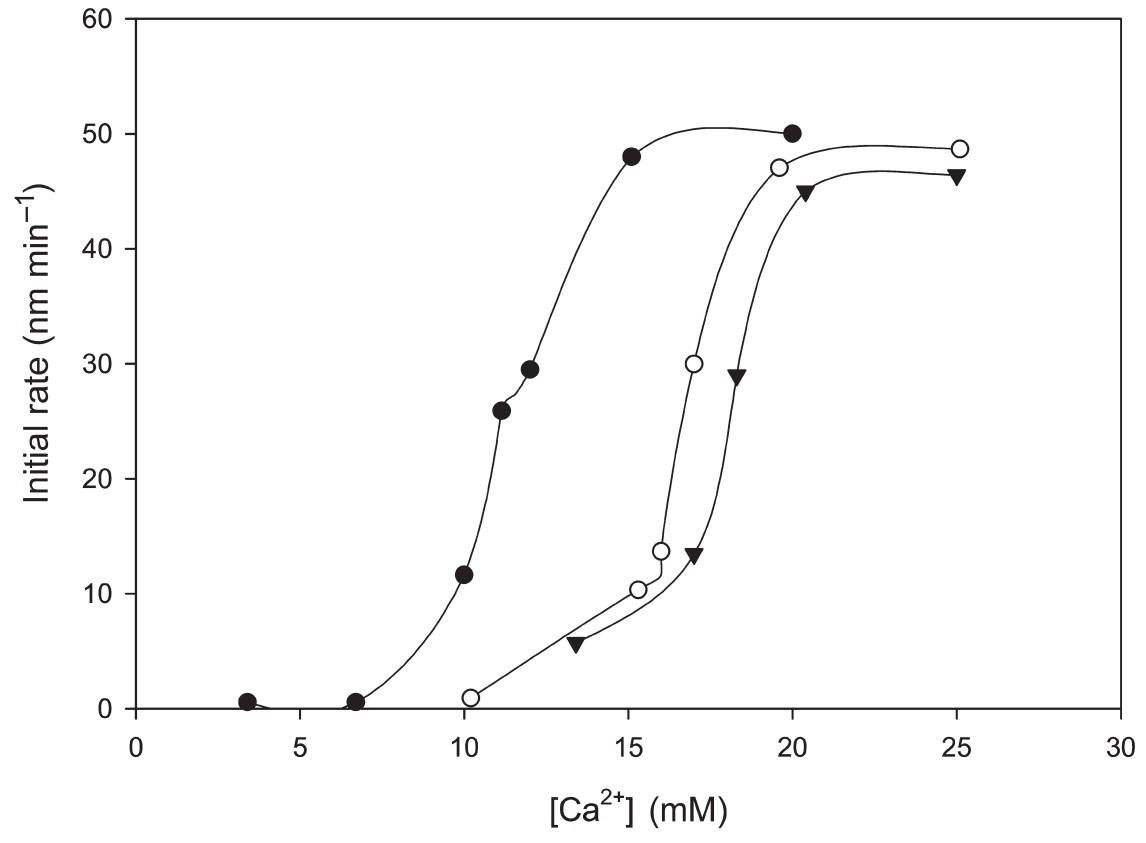

Figure 6. Plots of the initial rate of $\mathrm{Ca}^{2+}$-induced PLFE vesicle aggregation versus $\mathrm{Ca}^{2+}$ concentration $\left(\left[\mathrm{Ca}^{2+}\right]\right)$ at $25{ }^{\circ} \mathrm{C}(0), 40{ }^{\circ} \mathrm{C}(\bigcirc)$ and $54{ }^{\circ} \mathrm{C}(\boldsymbol{\nabla})$ in $50 \mathrm{mM} \mathrm{KCl}(\mathrm{pH} 6.6)$. 
Table 2. Effects of $\mathrm{pH}$ and temperature on the threshold $\mathrm{Ca}^{2+}$ concentration $\left(C_{\mathrm{r}}\right)$ for PLFE vesicle aggregation and on the surface potential $\left(\Psi_{\mathrm{o}}\right)$ of PLFE vesicles (117 $\mathrm{nm}$ in diameter) prior to aggregation.

\begin{tabular}{llll}
\hline $\mathrm{pH}$ & Temperature $\left({ }^{\circ} \mathrm{C}\right)$ & $C_{\mathrm{r}}(\mathrm{mM})$ & $\Psi_{\mathrm{o}}(\mathrm{mV})$ \\
\hline 6.6 & 25 & 11 & $-22.00 \pm 0.003$ \\
6.6 & 40 & 17 & $-13.20 \pm 5.30$ \\
6.6 & 54 & 18 & $-10.28 \pm 3.49$ \\
3.0 & 25 & 25 & $\mathrm{ND}^{1}$ \\
3.0 & 40 & 60 & $\mathrm{ND}$ \\
\hline
\end{tabular}

${ }^{1} \mathrm{ND}=$ not determined, because the TNS method works well only at neutral $\mathrm{pH}$.

branes are reduced as vesicle diameter decreases (Komatsu and Chong 1998). We cannot exclude the possibility that a temperature-induced change in lipid lateral organization (Bagatolli et al. 2000) (rather than transmembrane asymmetry) in the PLFE membrane affects TNS binding and fluorescence, thus changing the surface potential.

Archaeal bipolar tetraether liposomes have wide technological applications (Ring et al. 1986, Tomioka et al. 1994, Freisleben et al. 1995, Krishnan et al. 2000, Patel et al. 2000) because they are thermo- and acid-stable and resistant to mechanical stress and the actions of phospholipases, bile salts and serum proteins (reviewed in Gliozzi and Relini 1996). In a previous study (Komatsu and Chong 1998), we showed that small PLFE liposomes (diameter $\sim 60 \mathrm{~nm}$ ) exhibited lower proton permeability than large PLFE liposomes (diameter $\sim 240 \mathrm{~nm}$ ). Furthermore, the proton permeability of small PLFE liposomes is less sensitive to temperature than that of PLFE large unilamellar vesicles, changing by less than $2 \times 10^{-10} \mathrm{~cm}$ $\mathrm{s}^{-1}$ from 25 to $82{ }^{\circ} \mathrm{C}$ (Komatsu and Chong 1998). The photon correlation spectroscopic data in this study (Figure 1) provide evidence that the size of PLFE SUVs ( $87-90 \mathrm{~nm}$ in diameter) is extraordinarily stable for at least 6 months. All of these properties suggest that PLFE SUVs could be developed for applications such as drug delivery and bioassays. The high stability of PLFE SUVs should result in a long circulation time in vivo when these liposomes are used as drug or vaccine delivery vehicles. However, if the vesicles are extraordinarily stable, the entrapped materials cannot easily be released. According to our study, elevation of the local $\mathrm{Ca}^{2+}$ concentration in the target tissue could circumvent this problem by causing PLFE liposomes to undergo slow and limited vesicle fusion or coalescence to release the entrapped materials. The high $\mathrm{Ca}^{2+}$ concentration and long incubation time used in this study may be unrealistic for medical applications; however, mixtures of PLFE with phosphatidylethanolamines, which are known to facilitate membrane fusion and leakage, may enable controlled release of entrapped materials under physiological conditions. Whether aggregation, fusion or coalescence of PLFE liposomes occurs in the presence of other divalent cations or fusogenic agents has yet to be determined.

\section{Acknowledgments}

This work was supported in part by a grant from the NSF (MCB-9513669) and a grant from the U.S. Army Research Office (DAAD19-02-1-0077).

\section{References}

Bagatolli, L., E. Gratton, T.P. Khan and P.L.-G. Chong. 2000. Twophoton fluorescence microscopy studies of bipolar tetraether giant liposomes from thermoacidophilic archaebacteria Sulfolobus acidocaldarius. Biophys. J. 79:416-425.

Bauer, S., K. Heckmann, L. Six and C. Strobl. 1983. Hyperfiltration through crosslinked monolayers. II. Desalination 46:369-378.

Bentz, J. and N. Duzgunes. 1985. Fusogenic capacities of divalent cations and effect of liposome size. Biochemistry 24:5436-5443.

Boni, L.T., J.S. Hah, S.W. Hui, P. Mukherjee, J.T. Ho and C.Y. Jung. 1984. Aggregation and fusion of unilamellar vesicles by poly(ethylene glycol). Biochim. Biophys. Acta 775:409-418.

Brock, T.D., K.M. Brock, R.T. Belly and R.L. Weiss. 1972. Sulfolobus: a new genus of sulfur-oxidizing bacteria living at low $\mathrm{pH}$ and high temperature. Arch. Mikrobiol. 84:54-68.

Cafiso, D., A. McLaughlin, S. McLaughlin and A. Winiski. 1989. Measuring electrostatic potentials adjacent to membranes. Methods Enzymol. 171:342-364.

Chang, E.L. 1994. Unusual thermal stability of liposomes made from bipolar tetraether lipids. Biochem. Biophys. Res. Commun. 202: 673-679.

Chang, E.L. and S.-L. Lo. 1991. Extraction and purification of tetraether lipids from Sulfolobus acidocaldarius. In Protocols for Archaebacterial Research. Eds. E.M. Fleischmann, A.R. Place, R.T. Robb and H.J. Schreier. Maryland Biotechnology Institute, Univ. Maryland System, Baltimore, MD, pp 2.3.1-2.3.14.

Choquet, C.G., G.B. Patel, T.J. Beveridge and G.D. Sprott. 1994. Stability of pressure-extruded liposomes made from archaebacterial ether lipids. Appl. Microbiol. Biotechnol. 42:375-384.

De Rosa, M., E. Esposito, A. Gambacorta, B. Nicholaus and J.D. Bu'Lock. 1980. Effects of temperature on ether lipid composition of Caldariella acidophila. Phytochemistry 19:827-831.

De Rosa, M., A. Gambacorta and B. Nicolaus. 1983. A new type of cell membrane in thermophilic archaebacteria, based on bipolar ether lipids. J. Membr. Sci. 16:287-294.

De Rosa, M., A. Gambacorta and A. Gliozzi. 1986. Structure, biosynthesis and physicochemical properties of archaebacterial lipids. Microbiol. Rev. 50:70-80.

Easter, J.H., R.P. Detoma and L. Brand. 1978. Fluorescence measurements of environmental relaxation at the lipid-water interface region of bilayer membranes. Biochim. Biophys. Acta 508:27-38.

Eisenberg, M., T. Gresalfi, T. Riccio and S. McLaughlin. 1979. Adsorption of monovalent cations to bilayer membranes containing negative phospholipids. Biochemistry 18:5213-5223.

Elferink, M.G.L., J.G. de Wit, R. Demel, A.J.M. Driessen and W.N. Konings. 1992. Functional reconstitution of membrane proteins in monolayer liposomes from bipolar lipids of Sulfolobus acidocaldarius. J. Biol. Chem. 267:1375-1381.

Elferink, M.G.L., J.G. de Wit, A.J.M. Driessen and W.N. Konings. 1994. Stability and proton-permeability of liposomes composed of archaeal tetraether lipids. Biochim. Biophys. Acta 1193:247-254.

Ellens, H., D.P. Siegel, D. Alford, P.L. Yeagle, L. Boni, L.J. Lis, P.J. Quinn and J. Bentz. 1989. Membrane fusion and inverted phases. Biochemistry 28:3692-3703.

Freisleben, H.-J., J. Bormann, D.C. Litzinger, F. Lehr, P. Rudolph, M. Schatton and L. Huang. 1995. Toxicity and biodistribution of liposomes of the main phospholipid from the archaebacterium Thermoplasma acidophilum. J. Liposome Res. 5:215-223. 
Gabriel, J.L. and P.L.-G. Chong. 2000. Molecular modeling of archaebacterial bipolar tetraether liposomes by perylene fluorescence. Chem. Phys. Lipids 105:193-200.

Gliozzi, A. and A. Relini. 1996. Lipid vesicles as model systems for archaea membranes. In Handbook of Nonmedical Applications of Liposomes. Vol. II. Eds. Y. Barenholz and D.D. Lasic. CRC Press, Boca Raton, FL, pp 329-348.

Gliozzi, A., A. Relini and P.L.-G. Chong. 2002. Structure and permeability properties of biomimetic membranes of bolaform archaeal tetraether lipids. J. Membr. Sci. 206:131-147.

Gulik, A., V. Luzzati, M. de Rosa and A. Gambacorta. 1988. Tetraether lipid components from a thermoacidophilic archaebacterium. J. Mol. Biol. 201:429-435.

Hope, M.J, M.B. Bally, G. Webb and P.R. Cullis. 1985. Production of large unilamellar vesicles by a rapid extrusion procedure. Characterization of size distribution, trapped volume and ability to maintain a membrane potential. Biochim. Biophys. Acta 812:55-65.

Huang, C.H. and J.P. Charlton. 1972. Interactions of phosphatidylcholine vesicles with 2-p-toluidinylnaphthalene-6-sulfonate. Biochemistry 11:735-740.

Hui, S.W., T.P. Stewart, L.T. Boni and P.L. Yeagle. 1981. Membrane fusion through point defects in bilayers. Science 212:921-923.

Hui, S.W., S. Nir, T.P. Stewart, L.T. Boni and S.K. Haung. 1988. Kinetic measurements of fusion of phosphatidylserine-containing vesicles by electron microscopy and fluorometry. Biochim. Biophys. Acta 941:130-140.

In't Veld, G., M.G.L. Elferink, A.J.M. Driessen and W.N. Konings. 1992. Reconstitution of the leucine transport system of Lactococcus lactis into liposomes composed of membrane-spanning lipids from Sulfolobus acidocaldarius. Biochemistry 31: 12,493-12,499.

Kates, M. 1992. Archaebacterial lipids: structure, biosynthesis and function. In The Archaebacteria: Biochemistry and Biotechnology. Eds. M.J. Danson, D.W. Hough and G.G. Lunt. Portland Press, London, pp 51-72.

Kao, Y.L., E.L. Chang and P.L.-G. Chong. 1992. Unusual pressure dependence of the lateral motions of pyrene-labeled phosphatidylcholine in bipolar lipid vesicles. Biochem. Biophys. Res. Commun. 188:1241-1246.

Khan, T.K. and P.L.-G. Chong. 2000. Studies of archaebacterial bipolar tetraether liposomes by perylene fluorescence. Biophys. J. 78: 1390-1399.

Komatsu, H. and P.L.-G. Chong. 1998. Low permeability of liposomal membranes composed of bipolar tetraether lipids from thermoacidophilic archaebacterium Sulfolobus acidocaldarius. Biochemistry 37:107-115.

Krishnan, L., C.J. Dicaire, G.B. Patel and G.D. Sprott. 2000. Archaeosome vaccine adjuvants induce strong humoral, cell-mediated, and memory responses: comparison to conventional liposomes and alum. Infect. Immun. 68:54-63.

Lakowicz, J.R. and D. Hogen. 1981. Dynamic properties of the lipid-water interface of model membranes as revealed by lifetime-resolved fluorescence emission spectra. Biochemistry 20: 1366-1373.

Langworthy, T.A. and J.L. Pond. 1986. Membranes and lipids of thermophiles. In Thermophiles: General, Molecular, and Applied Microbiology. Ed. T.D. Brock. John Wiley \& Sons, New York, pp 107-134.

Leventis, R., J. Gagne, N. Fuller, R.P. Rand and J.R. Silvius. 1986. Divalent cation induced fusion and lipid lateral segregation in phosphatidylcholine-phosphatidic acid vesicles. Biochemistry 25: 6978-6987.
Lo, S.-L. and E.L. Chang. 1990. Purification and characterization of a liposomal-forming tetraether lipid fraction. Biochem. Biophys. Res. Commun. 167:238-243.

Papahadjopoulos, D., W.J. Vail, C. Newton, S. Nir, K. Jacobson, G. Poste and R. Lazo. 1977. Studies on membrane fusion. III. The role of calcium-induced phase changes. Biochim. Biophys. Acta 465:579-598.

Papahadjopoulos, D., S. Nir and N. Duzgunes. 1990. Molecular mechanisms of calcium-induced membrane fusion. J. Bioenerg. Biomembr. 22:157-179.

Patel, G.B., B.J. Agnew, L. Deschatelets, L.P. Fleming and G.D. Sprott. 2000. In vitro assessment of archaeosome stability for developing oral delivery systems. Int. J. Pharm. 194:39-49.

Relini, A., D. Cassinadri, Z. Mirghani, O. Brandt, A. Gambacorta, A. Trincone, M. De Rosa and A. Gliozzi. 1994. Calcium-induced interaction and fusion of archaeobacterial lipid vesicles: a fluorescence study. Biochim. Biophys. Acta 1194:17-24.

Relini, A., D. Cassinadri, Q. Fan, A. Gulik, Z. Mirghani, M. De Rosa and A. Gliozzi. 1996. Effect of physical constraints on the mechanisms of membrane fusion: bolaform lipid vesicles as model systems. Biophys. J. 71:1789-1795.

Ring, K., B. Henkel, A. Valenteijn and R. Gutermann. 1986. Studies on the permeability and stability of liposomes derived from a membrane-spanning bipolar archaebacterial tetraether lipid. In Liposomes as Drug Carriers. Ed. K.H. Schmidt. Georg Thieme Verlag, Stuttgart, pp 100-123.

Seelig, J. and P. Ganz. 1991. Nonclassical hydrophobic effect in membrane binding equilibria. Biochemistry 30:9354-9359.

Sprott, G.D. 1992. Structures of archaebacterial membrane lipids. J. Bioenerg. Biomembr. 24:555-566.

Sprott, G.D., D.L. Tolson and G.B. Patel. 1997. Archaeosomes as novel antigen delivery systems. FEMS Microbiol. Lett. 154: $17-22$.

Sugai, A., R. Sakuma, I. Fukuda, N. Kurosawa, Y.H. Itoh, K. Kon, S. Ando and T. Itoh. 1995. The structure of the core polyol of the ether lipids from Sulfolobus acidocaldarius. Lipids 30:339-344.

Sundler, R. and D. Papahadjopoulos. 1981. Control of membrane fusion by phospholipid headgroups. I. Phosphatidate/phosphatidylinositol specificity. Biochim. Biophys. Acta 649:743-750.

Tomioka, K., F. Kii, H. Fukuda and S. Katoh. 1994. Homogeneous immunoassay of antibody by use of liposomes made of a model lipid of archaebacteria. J. Immunol. Methods 176:1-7.

van de Vossenberg, J.L.C.M., T. Ubbink-Kok, M.G.L. Elferink, A.J.M. Driessen and W.N. Konings. 1995. Ion permeability of the cytoplasmic membrane limits the maximum growth temperature of bacteria and archaea. Mol. Microbiol. 18:925-932.

Weast, R.C. 1987. Handbook of chemistry and physics. 68th Edn. CRC Press, Boca Raton, FL, pp E-374 and F-39.

Wilschut J., N. Duzgunes, R. Fraley and D. Papahadjopoulos. 1980. Studies on the mechanism of membrane fusion: kinetics of calcium ion induced fusion of phosphatidylserine vesicles followed by a new assay for mixing of aqueous vesicle contents. Biochemistry 19:6011-6021.

Wilschut J., N. Duzgunes and D. Papahadjopoulos. 1981. Calcium/ magnesium specificity in membrane fusion: kinetics of aggregation and fusion of phosphatidylserine vesicles and the role of bilayer curvature. Biochemistry 20:3126-3133.

Wilschut, J., S. Nir, J. Scholma and D. Hoekstra. 1985. Kinetics of $\mathrm{Ca}^{2+}$-induced fusion of cardiolipin-phosphatidylcholine vesicles: correlation between vesicle aggregation, bilayer destabilization and fusion. Biochemistry 24:4630-4636. 

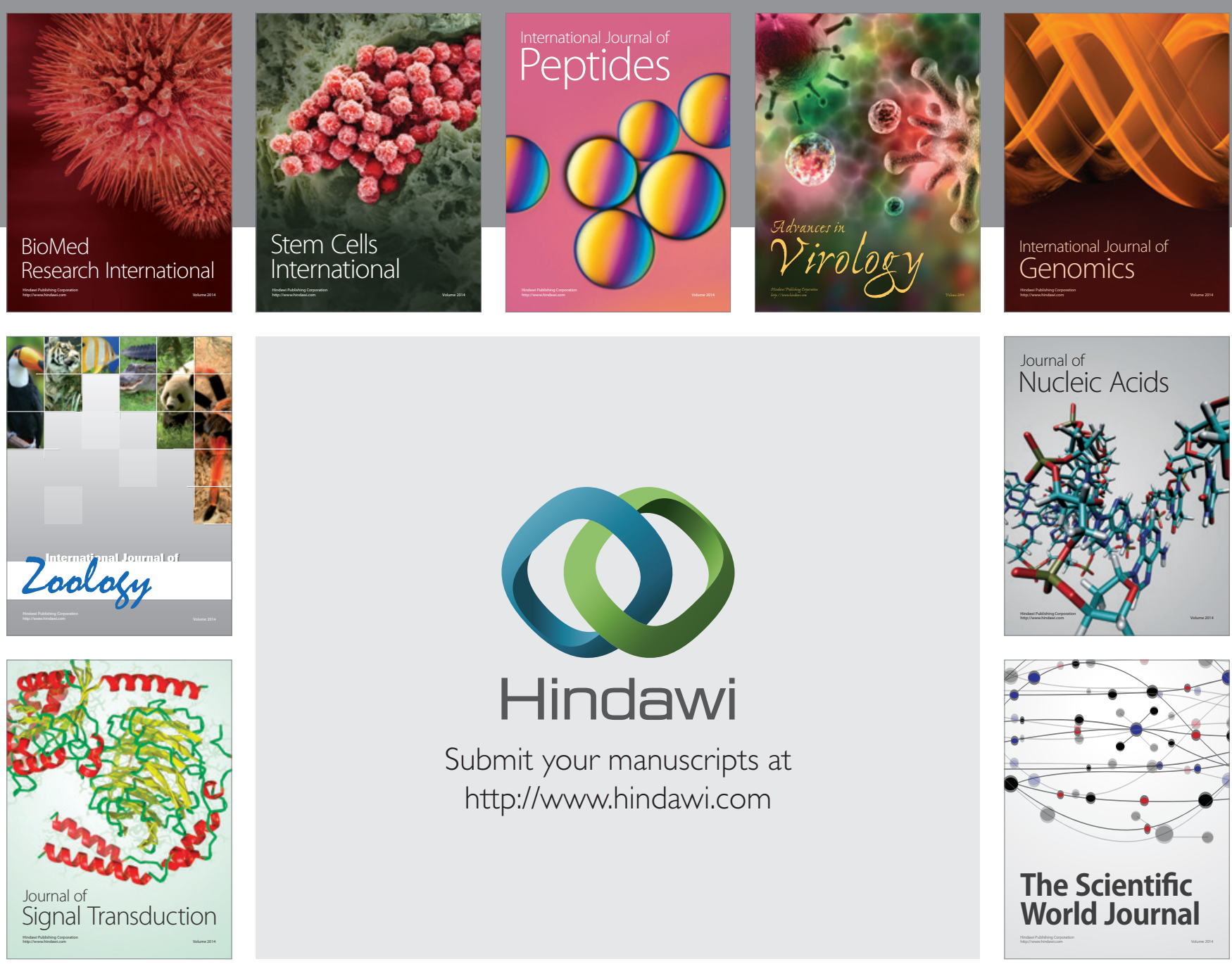

Submit your manuscripts at

http://www.hindawi.com
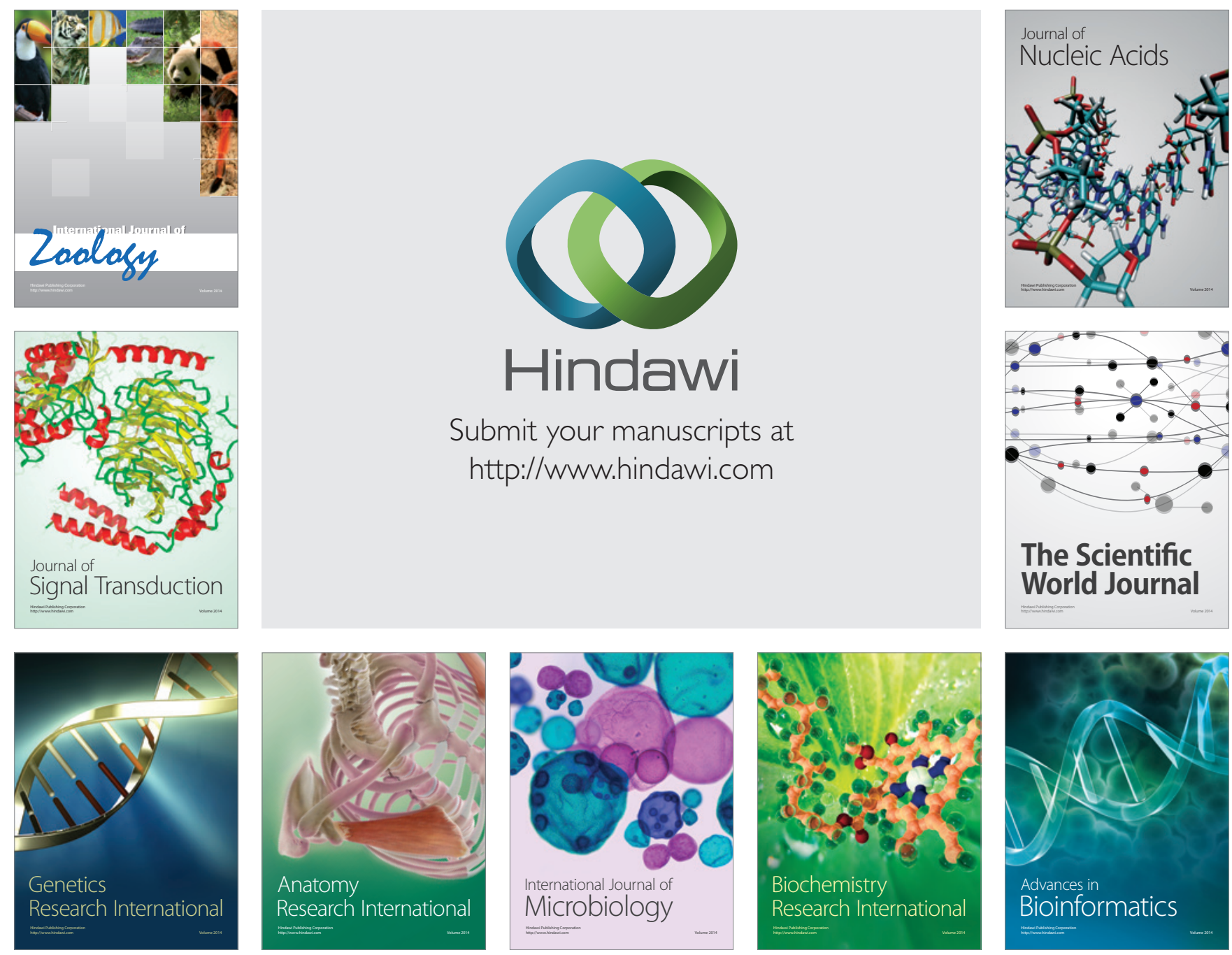

The Scientific World Journal
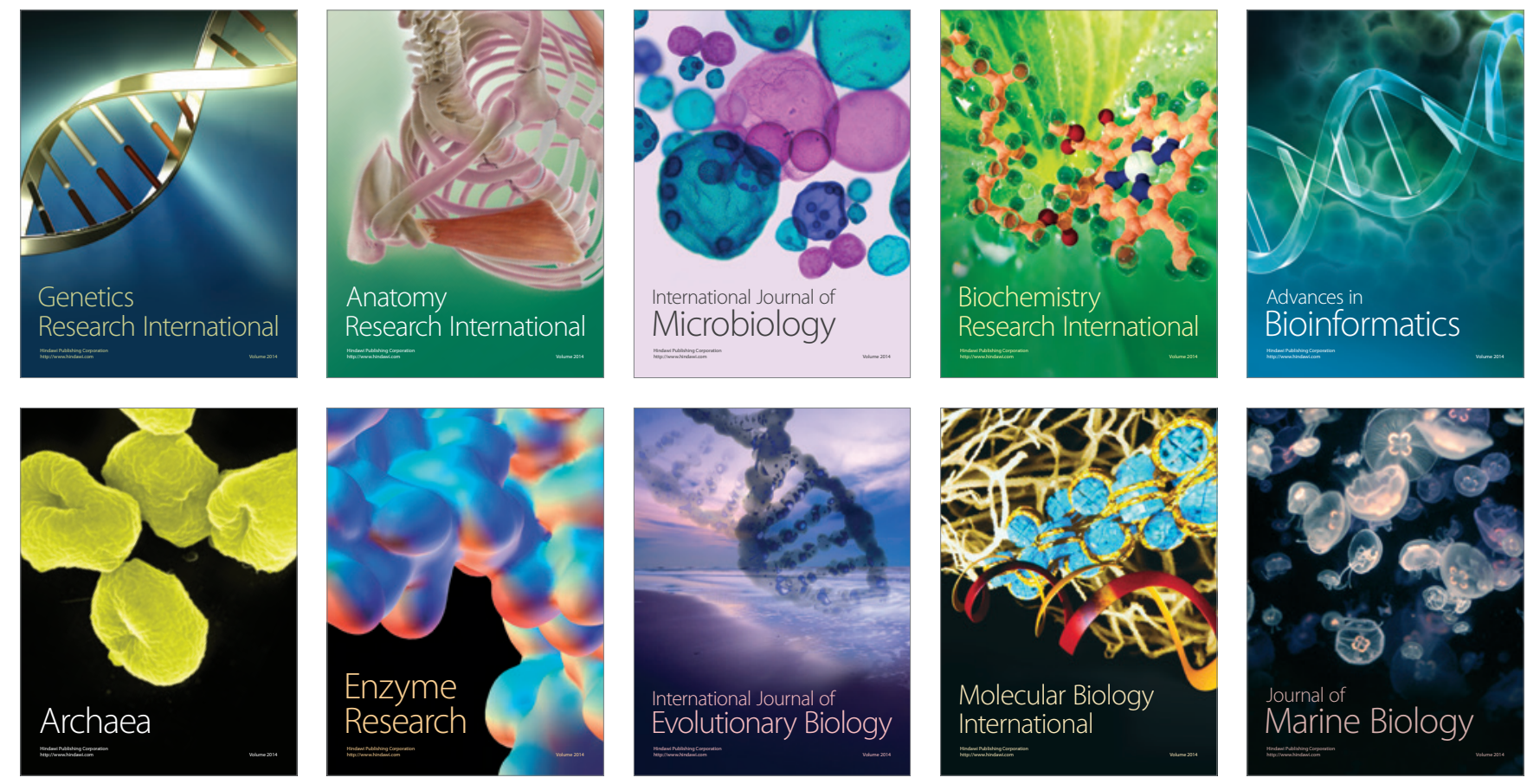